\title{
Assessing cannabis consumption frequency: Is the combined use of free and glucuronidated THCCOOH blood levels of diagnostic utility?
}

Authors:

Marianne Hädener ${ }^{1}$, Marie Martin Fabritius ${ }^{1}$, Stefan König ${ }^{1}$, Christian Giroud ${ }^{2}$, Wolfgang Weinmann $^{1}$

${ }^{1}$ Affiliation and Address:

Institute of Forensic Medicine

University of Bern

Bühlstrasse 20

3012 Bern

Switzerland

${ }^{2}$ Affiliation and Address:

Forensic Toxicology and Chemistry Unit

University Center of Legal Medicine

Chemin de la Vulliette 4

1000 Lausanne 25

Switzerland

Corresponding author:

Marianne Hädener

Institute of Forensic Medicine

University of Bern

Bühlstrasse 20

3012 Bern

Switzerland

E-mail address: marianne.haedener@irm.unibe.ch

Telephone number with country code: +41 (0)31 6313054

Fax number with country code: +41 (0)31 6318580 


\begin{abstract}
Heavy cannabis consumption is considered incompatible with safe driving. In Swiss traffic policy, drivers suspected of regular cannabis use are therefore required to undergo medical assessment of their long-term fitness to drive. A whole blood concentration of the cannabis metabolite 11-nor-9-carboxy- $\Delta^{9}$-tetrahydrocannabinol (THCCOOH) of $40 \mu \mathrm{g} / \mathrm{L}$ is currently used by Swiss forensic experts as decision limit for regular cannabis consumption. The present study aimed to investigate the suitability of THCCOOH-glucuronide blood levels as an additional and/or better marker for the frequency of cannabis use. Whole blood samples collected from 23 heavy ( $\geq 10$ joints/month) and 25 occasional smokers $(\geq 1$ joint/month, but $\leq 1$ joint/week) enrolled in a placebo-controlled cannabis smoking study were analyzed for THCCOOH and THCCOOH-glucuronide. Based on ROC curve analysis concentration thresholds could be established for distinguishing between these two groups. Proposed thresholds for heavy use were THCCOOH-glucuronide > $52 \mu \mathrm{g} / \mathrm{L}$ (100\% specificity; $41 \%$ sensitivity) and/or total THCCOOH $>58 \mu \mathrm{g} / \mathrm{L}$ (100\% specificity; 43\% sensitivity). Optimum thresholds for occasional use were THCCOOH-glucuronide $<5 \mu \mathrm{g} / \mathrm{L}$ (73\% specificity; 97\% sensitivity) and/or total THCCOOH $<5$ $\mu \mathrm{g} / \mathrm{L}$ (62\% specificity; $98 \%$ sensitivity). Our results indicate that the THCCOOH-glucuronide whole blood concentration is a useful parameter that complements the free THCCOOH level to assess the frequency of cannabis consumption. The consideration of the blood concentrations of both free and glucuronidated THCCOOH improves the identification of heavy users whose fitness to drive has to be carefully assessed.
\end{abstract}

\title{
Keywords
}

THCCOOH, THCCOOH-glucuronide, cannabis, consumption frequency, whole blood 


\section{Introduction}

Drug-impaired driving poses a serious threat to global road safety. ${ }^{[1,2]}$ Driving under the influence of cannabis (DUIC) is of particular concern, since cannabis is the most widely abused illicit drug worldwide ${ }^{[3]}$ and is clearly the most frequently encountered illicit drug in the blood of impaired and fatally injured drivers. ${ }^{[4-10]}$ Numerous studies have investigated the effects of cannabis on short and long-term driving performance, as published in a recent review article. ${ }^{[11]}$ Epidemiologic data show that the risk of being involved in a motor vehicle accident approximately doubles after cannabis consumption. Experimental studies, using cognitive and psychomotor tests, driving simulators as well as driving tests on closed courses and the open road, have confirmed that cannabis adversely affects cognitive functions and psychomotor skills required for safe driving (e.g. attention, reaction time, perception, motor skills). These findings clearly underline the need for effective laws and legal regulations to address the issue of DUIC. Switzerland, among several other European countries, ${ }^{[12]}$ has adopted a zero tolerance policy toward DUIC wherein any amount of psychoactive $\Delta^{9}$-tetrahydrocannabinol (THC) in blood above the analytical detection limit of $1.5 \mu \mathrm{g} / \mathrm{L}$ is deemed proof of the driver's acute impairment and inability to drive. Legal consequences of DUIC include suspension of the driver's license for several months, a fine, procedural costs, and usually a medical assessment of the long-term fitness to drive. Since chronic cannabis consumption suggests an issue of drug addiction, drivers suspected of regular cannabis use are required to undergo medical assessment of their fitness to drive, even if no THC was detected in their blood. ${ }^{[13]}$ According to the Swiss Road Traffic Act drug dependence is incompatible with safe driving and disqualifies a person from holding or obtaining a driver's license. ${ }^{[14]}$ If the medical assessment confirms cannabis dependence and unfitness to drive, the driver faces a suspension of the driver's license for an indefinite period of time and must undergo outpatient drug abuse treatment. The driver's license may be reinstated after proving twelve months' abstinence by regular urine and/or blood samples. Occasional cannabis consumption, on the other hand, is not considered to affect the long-term fitness to drive. As long as occasional users do not drive under the acute influence of cannabis, they do not represent a severe risk to road safety. In Swiss traffic policy, a reliable distinction between occasional and heavy cannabis users is thus mandatory within the context of assessing fitness to drive.

Due to its long elimination half-life, ${ }^{[15]}$ 11-nor-9-carboxy-THC (THCCOOH), a major phase I metabolite of THC, accumulates in the blood upon frequent use. ${ }^{[16-20]}$ Fabritius et al. ${ }^{[21]}$ recently showed that THCCOOH blood levels below $3 \mu \mathrm{g} / \mathrm{L}$ are correlated with an occasional use $(\geq 1$ joint/month, but $\leq 1$ joint/week), whereas concentrations higher than $40 \mu \mathrm{g} / \mathrm{L}$ are indicative of heavy consumption ( $\geq 10$ joints/month). Upon the recommendation of the Swiss Society of Legal Medicine, ${ }^{[13]}$ this threshold of $40 \mu \mathrm{g} / \mathrm{L}$ is currently used by Swiss forensic experts to classify suspected impaired drivers as regular cannabis users whose fitness to drive has to be carefully assessed. On the basis of the definitions used by Fabritius et al., ${ }^{[21]}$ the Swiss Society of Legal Medicine agreed on defining occasional cannabis use as "up to twice a week" and regular use as "more than twice a week". ${ }^{[13]}$ The use of THCCOOH blood levels as indicator for the cannabis 
consumption frequency has also been advocated in Germany ${ }^{[22]}$ and France. ${ }^{[23]}$ However, at the moment there is no international agreement, neither on the proposed cutoff concentrations, nor on the definition of occasional, regular and heavy cannabis use. ${ }^{[24]}$

In the study performed by Fabritius et al. ${ }^{[21]} 84 \%$ of the heavy smokers' blood samples had $\mathrm{THCCOOH} \leq 40 \mu \mathrm{g} / \mathrm{L}$, implying that the cutoff's sensitivity to detect heavy users is rather low. Furthermore, THCCOOH blood levels lying between 3 and $40 \mu \mathrm{g} / \mathrm{L}$ did not allow for a clear conclusion regarding the frequency of cannabis use. We assume that this rather modest diagnostic performance of the THCCOOH blood concentration to discriminate between occasional and heavy cannabis use can be attributed to the fact that $\mathrm{THCCOOH}$ undergoes extensive phase II metabolism based on its conjugation with glucuronic acid. ${ }^{[15,25]}$ In several controlled THC administration studies, when considering the same time point, the ratio of glucuronidated to free THCCOOH in plasma or whole blood showed a high variability across participants, $\left.{ }^{[16,} 20,25,26\right]$ suggesting that interindividual differences in the glucuronidation and elimination rate are prominent. Therefore, the THCCOOH blood level is not only determined by the consumption frequency, but also depends on the glucuronidation efficiency and kinetics. Sample collection, storage and processing conditions are other important factors influencing the amount of free THCCOOH since THCCOOH-glucuronide has limited stability and is prone to deconjugation. ${ }^{\text {[27- }}$ ${ }^{31]}$ As reported for $\mathrm{THCCOOH},{ }^{[16-18,20]}$ plasma, serum and whole blood concentrations of THCCOOH-glucuronide were higher in heavy cannabis users than in occasional smokers. ${ }^{[16,18,20]}$ Based on these findings, we hypothesize that $\mathrm{THCCOOH}$-glucuronide blood concentration is a valuable supplemental marker for assessing the frequency of cannabis consumption and that the combined use of $\mathrm{THCCOOH}$ and $\mathrm{THCCOOH}$-glucuronide blood levels, while retaining maximum specificity, will increase the diagnostic sensitivity for the detection of regular cannabis users. To test this hypothesis, we recently developed a liquid chromatography-tandem mass spectrometry (LC-MS/MS) method for the rapid and simultaneous quantification of $\mathrm{THCCOOH}$ and THCCOOH-glucuronide in blood. ${ }^{[32]}$

In the present work, we measured $\mathrm{THCCOOH}$ and $\mathrm{THCCOOH}$-glucuronide concentrations in blood samples collected from 23 heavy and 25 occasional smokers during a placebo-controlled cannabis smoking study. Using receiver operating characteristic (ROC) curve analysis, we attempted to determine the best decision threshold concentrations for THCCOOH-glucuronide and total $\mathrm{THCCOOH}$ for discriminating between occasional and heavy use. 


\section{Experimental}

\section{Study design and blood collection}

The present work is based on a previously published placebo-controlled cannabis smoking study which comprised various neuroimaging and psychomotor investigations, along with toxicological analyses of whole blood and oral fluid samples. ${ }^{[21,33-35]}$ The study's objectives and procedures were reviewed and approved by the Cantonal Research Ethics Committee (Canton of Vaud). Subjects provided written informed consent and received financial compensation for their participation. The overall study design has been detailed by Battistella et al. ${ }^{[33]}$ and is briefly described below.

The final study population for the toxicological investigations included 23 heavy smokers and 25 occasional smokers (healthy males, ages 18 - 30 years) who met the following criteria: selfreported average frequency of cannabis consumption of at least one joint per month and at most one joint per week (occasional smokers) or at least ten joints per month (heavy smokers) during the three months prior to the study. Very heavy cannabis smokers ( $>3$ joints/day) were excluded from the study, as they were considered unable to abstain from cannabis smoking during the allday experimental sessions, particularly during the placebo session. Subjects consuming any illegal drug other than cannabis were also disqualified from participation. Subjects were requested to abstain from smoking cannabis and tobacco for at least 12 hours prior to the experimental days.

The study comprised two independent cross-over experimental sessions, separated by one week in which participants smoked either a cigarette of pure cannabis $(0.7 \mathrm{~g}$ Bedrobinol, $11 \% \mathrm{THC}$, < $1 \% \mathrm{CBD})$ or a placebo (0.8 $\mathrm{g}$ Santhica variety, no THC, $<0.1 \% \mathrm{CBD})$ according to a fixed-paced puffing procedure. The smoked amount of THC averaged about $42 \mathrm{mg}$. Whole blood samples were taken during the screening visit, on admission ( $5 \mathrm{~h}$ before smoking), a few minutes $(\mathrm{t}=0 \mathrm{~h})$ before inhalation, and $0.2,0.3,0.4,0.65,1.9,2.5$, and $3.5 \mathrm{~h}$ after the start of smoking (actual times of blood sampling varied slightly among participants). For occasional smokers, experimental sessions should last no more than $3 \mathrm{~h}$ after inhalation, thus making the collection of the last blood sample impossible. Blood samples were collected in S-monovette ${ }^{\circledR}$ tubes (Sarstedt, Sevelen, Switzerland) containing EDTA/fluoride as anticoagulant and enzyme inhibitor and were stored at $-80{ }^{\circ} \mathrm{C}$ before and after analysis.

\section{Determination of blood cannabinoid concentrations}

Whole blood THCCOOH concentrations were measured within a few days after blood collection by GC- or LC-MS/MS as described by Fabritius et al. ${ }^{[21]}$ For the present study, the occasional and heavy smokers' blood samples were thawed after storage at $-80{ }^{\circ} \mathrm{C}$ and were re-analyzed by a recently developed LC-MS/MS method for rapid and simultaneous quantification of free and glucuronidated THCCOOH. ${ }^{[32]}$ Briefly, $100 \mu \mathrm{L}$ of whole blood samples were aliquoted into 96 well-plates and proteins were precipitated by adding $300 \mu \mathrm{L}$ of cold acetonitrile containing the two deuterated internal standards. After mixing and centrifugation, $40 \mu \mathrm{L}$ of the supernatant were 
directly injected onto the LC-MS/MS instrument. Linearity ranged from $5-500 \mu \mathrm{g} / \mathrm{L}$ for both analytes [the lowest calibrator being the lower limit of quantification (LLOQ)]. THCCOOH concentrations measured in the present study showed little deviation (median: $2.1 \%$ ) from the concentrations determined shortly after blood sampling by Fabritius et al. ${ }^{[21]}$ and therefore prove stability of the blood samples for the time period between sampling and re-analysis.

\section{Data analysis}

Data were analyzed using Microsoft Excel 2010 and GraphPad Prism 6.05 softwares for Windows. Unless otherwise specified, all data points were employed in statistical analyses, including estimates below the LLOQ and non-detectable concentrations. The latter ones were set to zero. Pharmacokinetic parameters, including highest observed concentrations $\left(\mathrm{C}_{\max }\right)$ after smoking, time at $\mathrm{C}_{\max }\left(\mathrm{t}_{\max }\right)$, concentrations at each time point, and glucuronide/free $\mathrm{THCCOOH}$ ratios were compared between occasional and heavy smokers by use of the Mann-Whitney exact test. Significance was attributed at two-tailed $P<0.05$. Receiver operating characteristic (ROC) curve analysis was performed to determine optimal cutoff values to discriminate between heavy and occasional smokers. True positives (TP) were correctly classified smokers, i.e. heavy smokers with cannabinoid concentrations higher than the cutoff. False positives (FP) were incorrectly identified heavy smokers, i.e. occasional smokers with cannabinoid concentrations higher than the cutoff. True negatives (TN) were correctly rejected smokers, i.e. occasional smokers with cannabinoid concentrations lower than the threshold. False negatives (FN) were incorrectly rejected smokers, i.e. heavy smokers with cannabinoid levels lower than the threshold. Sensitivity (true heavy rate) and specificity (true occasional rate) were defined by the ratios $\mathrm{TP} /(\mathrm{TP}+\mathrm{FN})$ and $\mathrm{TN} /(\mathrm{TN}+\mathrm{FP})$, respectively. The overall ability of the cannabinoid blood level as diagnostic marker to discriminate between occasional and heavy smokers was evaluated by the area under the ROC curve (AUC). An AUC value close to 1 indicates an excellent discriminatory power, whereas a ROC curve coinciding with the diagonal (AUC $=0.5$ ) suggests no discrimination. ${ }^{[36]}$ Total $\mathrm{THCCOOH}$ concentration was determined by converting the sum of molar THCCOOH and THCCOOH-glucuronide concentrations into the mass concentration of free THCCOOH equivalents. The LLOQ of total THCCOOH was derived from the LLOQ of THCCOOH-glucuronide and was calculated to be $3.3 \mu \mathrm{g} / \mathrm{L}$ ( $5 \mu \mathrm{g} / \mathrm{L}$ of THCCOOHglucuronide is $9.6 \mathrm{nmol} / \mathrm{L}$ which corresponds to $3.3 \mu \mathrm{g} / \mathrm{L}$ of free $\mathrm{THCCOOH}$ equivalents). 


\section{Results and discussion}

\section{Study participants}

Twenty-three heavy and 25 occasional smokers, all men, participated in the study. Demographic characteristics and self-reported histories of cannabis use are detailed in Tables S1 and S2 (see supporting information). The two user groups were very similar with regard to the age on admission, body mass index, age at first cannabis use as well as the lifetime years smoked, but they clearly differed in their self-reported frequency of use. Heavy smokers consumed on [median (range)] $20.0(5-60)$ occasions per week during the three weeks preceding the study, whereas occasional smokers smoked $3.5(<1-8)$ times per month during the three months preceding the study. Joints were generally shared with $2.5(0-4)$ persons among heavy smokers and with $3.5(2-5)$ persons among occasional smokers. Considering this, all subjects included in the group of occasional users smoked one joint or less per week.

\section{Kinetic profiles and pharmacokinetic parameters of THCCOOH and THCCOOH-glucuronide}

Median time profiles of $\mathrm{THCCOOH}$ and $\mathrm{THCCOOH}$-glucuronide concentrations of heavy and occasional smokers, before and after smoking of a cannabis or placebo cigarette are presented in Figure 1. The kinetic profile of THCCOOH has been previously discussed in detail by Fabritius et al. ${ }^{[21]}$ THCCOOH-glucuronide concentrations were highly variable among participants, although they smoked the same amount of cannabis, which is likely due to prior cannabis experience (different smoking habits and inhalation techniques). Despite these wide interindividual variations, median $\mathrm{THCCOOH}$-glucuronide concentrations were found to be markedly higher in frequent smokers compared to occasional smokers at all time points, as observed by Desrosiers et $a l .{ }^{[20]}$ In the group of heavy smokers median THCCOOH-glucuronide concentrations were higher than free $\mathrm{THCCOOH}$ concentrations throughout the experiment timeframe. Conjugated THCCOOH levels decreased from [median (range)] $59.2 \mu \mathrm{g} / \mathrm{L}(10.5-$ $336.0 \mu \mathrm{g} / \mathrm{L})$ to $50.8 \mu \mathrm{g} / \mathrm{L}(7.9-275.0 \mu \mathrm{g} / \mathrm{L})$ before smoking the cannabis cigarette and slightly increased thereafter, reaching a maximum of $59.7 \mu \mathrm{g} / \mathrm{L}(20.8-358.0 \mu \mathrm{g} / \mathrm{L})$ within $2.0 \mathrm{~h}(0.3$ $3.5 \mathrm{~h}$ ) post-smoking, as indicated in Table 1. Several occasional smokers had undetectable THCCOOH-glucuronide blood levels on admission, resulting in a median of zero $\mu \mathrm{g} / \mathrm{L}$ prior to smoking. Glucuronide levels gradually increased post-smoking and remained elevated for the remainder of the experiment reaching a maximum of $15.9 \mu \mathrm{g} / \mathrm{L}(<\mathrm{LLOQ}-47.3 \mu \mathrm{g} / \mathrm{L})$ within 2.6 $\mathrm{h}(1.5-2.9 \mathrm{~h})$. At the end of the experiment timeframe THCCOOH-glucuronide concentrations exceeded those of free THCCOOH.

To our knowledge, only two studies have documented THCCOOH-glucuronide concentrations in whole blood following controlled cannabis smoking. Whereas in the study by Schwope et al. ${ }^{\text {[25] }}$ only chronic frequent smokers were recruited, Desrosiers et al. ${ }^{[20]}$ compared THCCOOHglucuronide pharmacokinetics in occasional and frequent smokers. In both studies, participants smoked a single 6.8\% THC (total amount: $54 \mathrm{mg}$ THC) cigarette ad libitum over $10 \mathrm{~min}$ and cannabinoid blood concentrations were monitored for up to $22 \mathrm{~h}$ and $30 \mathrm{~h}$, respectively, after 
smoking. For the heavy smokers they reported median (range) THCCOOH-glucuronide $\mathrm{C}_{\max }$ of $89 \mu \mathrm{g} / \mathrm{L}(46-220 \mu \mathrm{g} / \mathrm{L})^{[25]}$ and $74.3 \mu \mathrm{g} / \mathrm{L}(40.4-218 \mu \mathrm{g} / \mathrm{L})^{[20]}$, respectively. For the occasional smokers $\mathrm{C}_{\max }$ was $16.2 \mu \mathrm{g} / \mathrm{L}(0-83.4 \mu \mathrm{g} / \mathrm{L}) .{ }^{[20]}$ In contrast to our study Schwope et al. ${ }^{[25]}$ and Desrosiers et al. ${ }^{[20]}$ included very heavy cannabis smokers with a self-reported average cannabis use $\geq 3$ joints/day (median was 5.5 joints/day and 4.5 joints/day, respectively). For the occasional users the self-reported average consumption frequency should not exceed 1 time/week in our study, whereas Desrosiers et al. ${ }^{[20]}$ restricted it to up to 2 times/week. In our view, the lower median THCCOOH-glucuronide $\mathrm{C}_{\max }$ values observed in this study are likely a consequence of the lower self-reported cannabis intake of our participants in the months preceding the experiment, resulting in lower THCCOOH-glucuronide baseline levels.

We also determined cannabinoid levels before and after smoking the placebo cigarette (Table 1). The majority of the occasional users' blood samples were free of THCCOOH-glucuronide during placebo conditions, resulting in median values of zero $\mu \mathrm{g} / \mathrm{L}$ for all time points. In the heavy users, THCCOOH-glucuronide was detectable in all samples within a range of < LLOQ - $191.0 \mu \mathrm{g} / \mathrm{L}$. Median (range) concentrations decreased from $41.5 \mu \mathrm{g} / \mathrm{L}$ ( $<\mathrm{LLOQ}-191.0 \mu \mathrm{g} / \mathrm{L})$ to $32.7 \mu \mathrm{g} / \mathrm{L}$ (< LLOQ - $119.0 \mu \mathrm{g} / \mathrm{L}$ ) between $5 \mathrm{~h}$ before and $3 \mathrm{~h}$ after smoking the placebo cigarette.

The blood sampling period of only $3.5 \mathrm{~h}$ after smoking was considered too short for reliable determination of the elimination half-life. Kelly et al. ${ }^{[16]}$ calculated in heavy users a terminal plasma THCCOOH-glucuronide elimination half-life of $6.8 \pm 4.5 \mathrm{~d}$, and of $3.7 \pm 2.0 \mathrm{~d}$ in occasional users based on an observation time period of $12 \mathrm{~d}$ after intravenous THC administration. For THCCOOH they found terminal elimination half-lives of $5.2 \pm 0.8 \mathrm{~d}$ and 6.2 $\pm 6.7 \mathrm{~d}$, respectively. Glaz-Sandberg et al. ${ }^{[37]}$ observed a terminal serum THCCOOH elimination half-life of $17.6 \pm 5.5 \mathrm{~h}$ in healthy, drug-free men, when monitoring THCCOOH concentrations up to $96 \mathrm{~h}$ after intravenous $\mathrm{THCCOOH}$ administration. Due to its high lipophilicity THC is rapidly and extensively distributed into adipose tissue ${ }^{[38,39]}$ from where it is slowly released back into the bloodstream and metabolized. ${ }^{[40,41]}$ This, as well as significant enterohepatic recirculation, ${ }^{[42-45]}$ are the main reasons for the long terminal elimination half-lives and the prolonged detection times of $\mathrm{THCCOOH}$ and $\mathrm{THCCOOH}$-glucuronide in blood. Regular cannabis use over an extended timeframe creates a heavy burden of cannabinoids in the body, which was illustrated by the high $\mathrm{THCCOOH}$-glucuronide baseline concentrations in the group of heavy smokers as observed in our study, by Schwope et al. ${ }^{[25]}$ and also by Desrosiers et al. ${ }^{[20]}$

\section{Glucuronide/free THCCOOH ratios}

We calculated glucuronide to free $\mathrm{THCCOOH}$ ratios based on molar concentrations before and after smoking of the cannabis cigarette (Figure 1). Ratios across time ranged from $0.15-4.99$ (median 1.17) in heavy users and from $0.05-2.65$ (median 0.49) in occasional users. Differences in ratios between the two user groups were significant $(\mathrm{P}<0.0001)$ at any time point after smoking. Ratios before smoking could only be reported for three occasional smokers since the other participants had undetectable THCCOOH and/or THCCOOH-glucuronide blood levels.

In both user groups, THCCOOH concentrations increased more rapidly than THCCOOHglucuronide concentrations post-smoking, leading to a brief decrease of the median 
glucuronide/free $\mathrm{THCCOOH}$ ratios immediately following smoking. As time passes, free THCCOOH underwent UGT-catalyzed glucuronidation ${ }^{[46]}$ and thus the ratios slowly increased, approaching baseline levels. This trend was previously reported by Schwope et al. ${ }^{[25]}$ and Desrosiers et $a l .{ }^{[20]}$ In agreement with their studies, we observed a high variability between participants at a given time point. In contrast to our findings, Desrosiers et al. ${ }^{[20]}$ observed higher ratios in occasional than in heavy users. However, they found no significant differences.

Schwope et al. ${ }^{[25]}$ reported ratios ranging from 0.43 to 5.3 (median 2.05) across participants and time of sampling and Desrosiers et al. ${ }^{[20]}$ observed ratios $>5$ on several occasions. These higher ratios were mainly found at time points exceeding our observation period $(>3.5 \mathrm{~h})$, i.e. during the late elimination phase.

Within the $5 \mathrm{~h}$ prior to smoking, the median ratio in the group of heavy smokers increased, suggesting gradual glucuronidation of free $\mathrm{THCCOOH}$. Since participants were admitted to the research unit only approximately $5 \mathrm{~h}$ before cannabis administration, some of the heavy smokers were possibly still intoxicated at the first time of cannabis dosing and were therefore in an early elimination phase.

Concentration differences for THCCOOH-glucuronide and total THCCOOH between occasional and heavy cannabis smokers

Concentrations of THCCOOH-glucuronide and total THCCOOH (sum of free and glucuronide) were found to be significantly higher in the group of heavy smokers than in occasional users $(P<$ $0.0001)$ at any time point of the two experimental sessions as well as during the initial screening visit. The results of the Mann-Whitney test are summarized in Table 1. The differences between the two groups for THCCOOH-glucuronide $t_{\max }$ were not significant, which is in agreement with the observations made by Desrosiers et al. ${ }^{[20]}$

A significant difference was also found when comparing the distribution of THCCOOHglucuronide and total $\mathrm{THCCOOH}$ blood levels between the two groups over the entire experiment timeframe, including the concentrations of the cannabis and placebo sessions and those measured during the screening visit (Figure 2). In the occasional users' blood samples the glucuronide concentrations ranged from $0-51.6 \mu \mathrm{g} / \mathrm{L}$, whereas for the heavy smokers the range was < LLOQ - 358.0 $\mu \mathrm{g} / \mathrm{L}$. Total THCCOOH concentrations ranged from $0-57.9 \mu \mathrm{g} / \mathrm{L}$ in the occasional users and from $3.4-377.3 \mu \mathrm{g} / \mathrm{L}$ in the heavy users.

Figure 2 reveals that there was a considerable overlap in the concentration ranges of the two groups of participants. This is due to the fact that $\mathrm{C}_{\max }$ values determined in the blood of occasional users were not significantly different from those measured in heavy smokers before smoking the cannabis cigarette or during the placebo session (Table 1).

\section{Determination of cutoff concentrations and optimal decision thresholds by ROC curve analysis}

Receiver operating characteristic (ROC) curve analyses were conducted to establish cutoff values and optimal decision threshold concentrations to discriminate between heavy and occasional smokers. Figure 3 presents the ROC curves obtained with all the THCCOOH-glucuronide and 
total THCCOOH concentrations measured throughout the study, including those of the placebo session and screening visit $(n=840)$. The occasional smokers were considered as control group, whereas the group of heavy smokers was defined as study group. The ROC curve is a plot of true positive rate (sensitivity) versus false positive rate (1-specificity) for different cutoff points. Thus, each point on the ROC curve represents a sensitivity/1-specificity pair associated with a particular discrimination threshold. The overall ability of the cannabinoid blood levels as diagnostic markers to discriminate between occasional and heavy smokers was evaluated by the area under the ROC curve (AUC). AUC was 0.96 and 0.94 , respectively, thus indicating that THCCOOH-glucuronide and total $\mathrm{THCCOOH}$ blood levels have a high discriminatory power for the recognition of heavy use, as previously hypothesized.

The best decision threshold should combine high sensitivity and maximum specificity. The choice of this decision limit is necessarily a sensitivity/specificity tradeoff: lowering the cutoff value to increase sensitivity will decrease specificity and vice versa. The appropriate balance between the two depends on the intended use of the diagnostic indicator. For our forensic purposes, high specificity is required to avoid a false accusation of chronic cannabis use. Therefore, the specificity for the identification of heavy smokers was set to $100 \%$ (false positive rate $=0 ; \mathrm{y}$-axis of the ROC-curve) and the cutoff was chosen to maximize sensitivity.

Specificities of $100 \%$ were obtained for cutoff concentrations higher than the observed maxima for occasional users', i.e. for THCOOH-glucuronide and total THCCOOH concentrations higher than $51.6 \mu \mathrm{g} / \mathrm{L}$ and $57.9 \mu \mathrm{g} / \mathrm{L}$, respectively (Figure 2). So we propose the following two blood concentration decision thresholds for discriminating heavy from occasional users: $52 \mu \mathrm{g} / \mathrm{L}$ of THCCOOH-glucuronide and $58 \mu \mathrm{g} / \mathrm{L}$ of total THCCOOH. ROC-curve analysis revealed that these thresholds are correlated with sensitivities of $41 \%$ and $43 \%$, respectively (Figure 3, circle 1). Thus, $59 \%$ and $57 \%$ of the heavy users' samples had blood levels $<52 \mu \mathrm{g} / \mathrm{L}$ of THCCOOHglucuronide and $<58 \mu \mathrm{g} / \mathrm{L}$ of total $\mathrm{THCCOOH}$, respectively.

In a similar way as Fabritius et al., ${ }^{[21]}$ we also tried to establish a decision limit that can be used to rule out heavy smokers. For this purpose, we determined the threshold that showed the closest sensitivity to $100 \%$ and was associated with the highest specificity (Figure 3, circle 2). For both the $\mathrm{THCCOOH}$-glucuronide and total $\mathrm{THCCOOH}$ blood level the optimal threshold to rule out heavy users was found to be $5 \mu \mathrm{g} / \mathrm{L}$. Specificities were $73 \%$ and $62 \%$, respectively, and sensitivities were $97 \%$ and $98 \%$, respectively. The diagnostic characteristics of the proposed decision thresholds to discriminate between occasional and heavy use are summarized in Table 2. Compared to the previously established threshold of $40 \mu \mathrm{g} / \mathrm{L}$ for free $\mathrm{THCCOOH},{ }^{[21]}$ these new decision limits for $\mathrm{THCCOOH}$-glucuronide and total $\mathrm{THCCOOH}$ blood concentrations offer much better sensitivities (Table 2). Thus, as stated in our working hypothesis, the use of these decision thresholds significantly improves the sensitivity of the detection of heavy users, however, with the constraint of measuring the concentrations of free THCCOOH and THCCOOH-glucuronide separately or together after hydrolysis.

Regarding the identification of occasional users (i.e. exclusion of heavy users), the decision limits assessed with blood THCCOOH-glucuronide and total THCCOOH ROC curves resulted in no appreciable improvement of the test performance compared to the criteria previously determined 
with the free $\mathrm{THCCOOH}$ blood concentration. In our study, 27\% of the occasional smokers' blood samples had THCCOOH-glucuronide levels higher than the proposed limit of $5 \mu \mathrm{g} / \mathrm{L}$. For the total $\mathrm{THCCOOH}$ threshold, the proportion was 38\%. As observed before with free THCCOOH blood thresholds, ${ }^{[21]}$ there was a gray zone of $\mathrm{THCCOOH}$-glucuronide and total $\mathrm{THCCOOH}$ concentrations which could not be reliably interpreted. This suggests that THCCOOH-glucuronide or total $\mathrm{THCCOOH}$ concentrations measured several hours to days after smoking can hardly be used to assess the frequency of cannabis use and to distinguish heavy from occasional cannabis smoking.

\section{Application of the proposed decision limits}

According to Swiss traffic policies, driving and cannabis consumption should be strictly separated. The more often a person consumes cannabis, the more likely he/she is to drive under the acute influence of cannabis. Compared to occasional users, regular users are assumed to be less able to separate cannabis consumption from driving. Since the ability to separate between cannabis consumption and driving is an important prerequisite for the fitness to drive, a medical assessment is required when regular cannabis use is suspected. The Swiss Society of Legal Medicine ${ }^{[13]}$ recommends that a THCCOOH blood concentration of $40 \mu \mathrm{g} / \mathrm{L}$ or higher should be considered as an indication for regular cannabis consumption, as proposed by Fabritius et al., ${ }^{\text {[21] }}$ and decided to define regular cannabis consumption as "more than twice a week" which is in agreement with the self-reported average frequency of cannabis use of the heavy smokers included in the study by Fabritius et al. ${ }^{[21]}$ ( $\geq 10$ joints/month, i.e. $\geq 2.3$ joints/week). At the moment, no international consensus on the definition of occasional, regular and heavy cannabis use exists. ${ }^{[24]}$

In the study conducted by Fabritius et al. ${ }^{[21]}$ the currently used THCCOOH threshold of $40 \mu \mathrm{g} / \mathrm{L}$ showed a sensitivity of only $16 \%$ for heavy cannabis use. Therefore, with the current procedure only a small percentage of the heavy cannabis users in Switzerland are correctly identified and referred for medical assessment of the fitness to drive. Since the proposed decision limits for THCCOOH-glucuronide and total $\mathrm{THCCOOH}$ are correlated with better sensitivities, they improve the detection of heavy users and are expected to result in a higher number of unfit drivers being prohibited from driving. In order to give a quantitative estimate of this improvement in Swiss forensic practice, we applied the newly proposed decision limits for heavy cannabis use to actual 926 suspected DUI cases. The drivers' whole blood specimens were submitted to our institute for routine analysis of THC, 11-OH-THC and THCCOOH by an established LC-MS/MS method. ${ }^{[30]}$ All drivers considered for this evaluation had detectable THCCOOH levels $(\geq 2.5 \mu \mathrm{g} / \mathrm{L})$, which identified them as cannabis consumers. To determine THCCOOH-glucuronide and total THCCOOH concentrations, the blood samples were reanalyzed with our recently developed LC-MS/MS method. ${ }^{[32]}$

About 50\% ( $n=469)$ of the drivers tested positive for THC in blood $(\geq 2.2 \mu \mathrm{g} / \mathrm{L})$. This THC positivity threshold corresponds to the Swiss analytical cutoff of $1.5 \mu \mathrm{g} / \mathrm{L}$ plus a confidence interval of $30 \%$ (i.e. $2.2 \mu \mathrm{g} / \mathrm{L}$ minus $30 \%$ is 1.54 which is just higher than the analytical cutoff of $1.5 \mu \mathrm{g} / \mathrm{L}$ ). Due to the Swiss zero tolerance policy for DUIC, these THC positive cases were 
reported to the administrative authorities and were referred for medical assessment of the longterm fitness to drive, irrespective of whether they were presumed to be heavy or occasional users. Thus, the impact of the proposed cutoff values in practice is better demonstrated with drivers who tested negative for THC $(<2.2 \mu \mathrm{g} / \mathrm{L})$.

Only $2 \%$ of the 457 THC negative drivers were suspected of heavy cannabis use by applying the previously established decision cutoff for free THCCOOH $(\geq 40 \mu \mathrm{g} / \mathrm{L})$. Taking into account our newly proposed decision limits for total THCCOOH blood level $(\geq 58 \mu \mathrm{g} / \mathrm{L})$, an additional $18 \%$ of the drivers would be classified as heavy users and therefore need to undergo medical assessment of their fitness to drive. When applying the proposed threshold for the THCCOOHglucuronide blood level ( $\geq 52 \mu \mathrm{g} / \mathrm{L}$ ), this would be $23 \%$. If medical assessment confirms heavy cannabis use and unfitness to drive, a considerable number of unfit drivers would be detected and prohibited from driving, which would be a clear benefit for road safety.

Another point in favor of using the newly proposed decision limits is the instability of THCCOOH-glucuronide. Under certain sample transport, storage and processing conditions, substantial deconjugation of THCCOOH-glucuronide can occur, leading to erroneously elevated blood concentrations of free $\mathrm{THCCOOH}{ }^{[27-31]}$, drivers being falsely classified as heavy users and drivers being classified differently by different laboratories since (pre-)analytical procedures can vary among laboratories. Therefore, taking into account the concentrations of both free and glucuronidated $\mathrm{THCCOOH}$, either by measuring free $\mathrm{THCCOOH}$ and $\mathrm{THCCOOH}$-glucuronide separately or together after hydrolysis, is highly advisable for a reliable assessment of the cannabis consumption frequency.

We are aware, that the validity and usefulness of the proposed decision limits used in the context of forensic practice need further evaluation and confirmation with more traffic offenders' cases.

\section{Strengths and limitations of the study design}

The study design ensured that a wide range of conditions encountered in forensic practice were taken into account. Samples collected during the placebo session presented blood concentrations typically found in the late elimination phase, whereas blood samples taken during the first $3 \mathrm{~h}$ following cannabis smoking reflected concentrations of the distribution and early elimination phase. Furthermore, two methods of administration were considered. Blood levels measured during the screening visit or during the placebo session resulted from ad libitum selfadministration, whereas blood levels determined after cannabis smoking were produced by controlled paced smoking. Consequently, we conclude that our study provides appropriate and reliable data for establishing decision limit concentrations to discriminate between occasional and heavy cannabis use. A limitation of the study is the short observation time period after smoking, which was due to the fact that experimental sessions had to be restricted to one day. ${ }^{[21]}$ If the blood sampling period had been longer, a higher number of lower concentrations would have been measured, thus lowering the sensitivities of the proposed decision limits for heavy cannabis use. The inclusion of very heavy cannabis users ( $>3$ joints/day), on the other hand, would probably have improved sensitivity. Another limitation is that the study included only male participants and there might be differences in sex due to the higher body fat percentage in 
women $^{[47]}$ and accumulation of cannabinoids in adipose tissue. ${ }^{[38,39]}$ Additional research is ongoing to determine the validity of the proposed cutoffs for female smokers and under further conditions such as different dosages, other administration routes (oral ingestion, vaporization) and simultaneous consumption of alcohol or other drugs that may interact with cannabis kinetics and effects. 


\section{Conclusions}

We evaluated the diagnostic value of THCCOOH-glucuronide and total THCCOOH concentrations in blood as criteria to distinguish heavy from occasional smokers. Based on ROC curve analysis, two decision limits were proposed: a THCCOOH-glucuronide blood level higher than $52 \mu \mathrm{g} / \mathrm{L}$ was found to be indicative of heavy use, whereas a concentration lower than $5 \mu \mathrm{g} / \mathrm{L}$ was correlated with occasional cannabis consumption. Regarding the total THCCOOH blood level we suggest $58 \mu \mathrm{g} / \mathrm{L}$ and $5 \mu \mathrm{g} / \mathrm{L}$ as thresholds for heavy and occasional consumption, respectively.

Since heavy cannabis consumption may cause long-term driving impairment, a medical assessment of the fitness to drive is compulsory in Switzerland for drivers suspected of heavy cannabis misuse. Diagnostic tools for the classification of impaired drivers as heavy or occasional users are thus important. In our opinion, the aforementioned decision limits could help to detect unfit drivers because of heavy cannabis use. To benefit from these new diagnostic tools, the separate determination of $\mathrm{THCCOOH}$ and $\mathrm{THCCOOH}$-glucuronide or of total $\mathrm{THCCOOH}$ in blood should become more common in forensic practice.

\section{Acknowledgment}

Professor Bernard Favrat, head of the Unit of Traffic Medicine and Psychology (UMPT) of the CURML Lausanne Geneva, is acknowledged for fruitful discussion.

\section{Conflict of interest}

The authors declare that they have no conflict of interest. 


\section{References}

[1] World Health Organization (WHO). Global status report on road safety 2015. Available at: http://www.who.int/violence_injury_prevention/road_safety_status/2015/en/ [26 January 2016].

[2] R. Penning, J.L. Veldstra, A.P. Daamen, B. Olivier, J.C. Verster. Drugs of abuse, driving and traffic safety. Curr. Drug. Abuse Rev. 2010, 3, 23.

[3] United Nations Office on Drugs and Crime (UNODC). World Drug Report 2015. Available at: http://www.unodc.org/documents/wdr2015/World_Drug_Report_2015.pdf [26 January 2016].

[4] European Monitoring Centre for Drugs and Drug Addiction (EMCDDA). Driving Under the Influence of Drugs, Alcohol and Medicines in Europe - findings from the DRUID project. 2012. Available at:

http://www.emcdda.europa.eu/attachements.cfm/att_192773_EN_TDXA12006ENN.pdf [26 January 2016].

[5] M.C. Senna, M. Augsburger, B. Aebi, T.A. Briellmann, N. Donze, J.L. Dubugnon, P.X. Iten, C. Staub, W. Sturm, K. Sutter. First nationwide study on driving under the influence of drugs in Switzerland. Forensic Sci. Int. 2010, 198, 11.

[6] A. Berning, R. Compton, K. Wochinger. National Highway Traffic Safety Administration (NHTSA). Results of the 2013-2014 National Roadside Survey of alcohol and drug use by drivers. 2015. Available at:

http://www.nhtsa.gov/Driving+Safety/Research+\&+Evaluation/Alcohol+and+Drug+Use+By+Dr ivers [26 January 2016]

[7] E.E. Beasley, D.J. Beirness. Alcohol and Drug Use Among Drivers Following the Introduction of Immediate Roadside Prohibitions in British Columbia: Findings from the 2012 Roadside Survey. 2012. Available at: http://www2.gov.bc.ca/assets/gov/driving-andtransportation/driving/publications/bc-roadside-report2012.pdf [26 January 2016]

[8] O.H. Drummer, I. Kourtis, J. Beyer, P. Tayler, M. Boorman, D. Gerostamoulos. The prevalence of drugs in injured drivers. Forensic Sci. Int. 2012, 215, 14.

[9] J.E. Brady, G. Li. Prevalence of alcohol and other drugs in fatally injured drivers. Addiction 2013, 108, 104.

[10] S. Elliott, H. Woolacott, R. Braithwaite. The prevalence of drugs and alcohol found in road traffic fatalities: a comparative study of victims. Sci. Justice 2009, 49, 19.

[11] R.L. Hartman, M.A. Huestis. Cannabis effects on driving skills. Clin. Chem. 2013, 59, 478.

[12] A.G. Verstraete, A. Knoche, R. Jantos, G. Skopp, H. Gjerde, V. Vindenes, J. Mørland, K. Langel, P. Lillsunde. Driving under the Influence of Drugs, Alcohol and Medicines (DRUID). Per se limits - Methods of defining cut-off values for zero tolerance. 2011. Available at: https://biblio.ugent.be/publication/1988464/file/1988490.pdf [27 January 2016]. 
[13] Swiss Society of Legal Medicine (SSML). Recommendations for assessing fitness to drive in the case of cannabis use. 2014. Available at:

http://www.sgrm.ch/uploads/media/THC_aemter_Info_d.pdf [22 September 2016]

[14] Swiss Federal Road Traffic Act. Available at: https://www.admin.ch/opc/de/classifiedcompilation/19580266/index.html [ 26 January 2016].

[15] M.A. Huestis. Human cannabinoid pharmacokinetics. Chem. Biodivers. 2007, 4, 1770.

[16] P. Kelly, R.T. Jones. Metabolism of tetrahydrocannabinol in frequent and infrequent marijuana users. J. Anal. Toxicol. 1992, 16, 228.

[17] S.W. Toennes, J.G. Ramaekers, E.L. Theunissen, M.R. Moeller, G.F. Kauert. Comparison of cannabinoid pharmacokinetic properties in occasional and heavy users smoking a marijuana or placebo joint. J. Anal. Toxicol. 2008, 32, 470.

[18] G. Skopp, L. Pötsch. Cannabinoid concentrations in spot serum samples 24-48 hours after discontinuation of cannabis smoking. J. Anal. Toxicol. 2008, 32, 160.

[19] M.M. Bergamaschi, E.L. Karschner, R.S. Goodwin, K.B. Scheidweiler, J. Hirvonen, R.H. Queiroz, M.A. Huestis. Impact of prolonged cannabinoid excretion in chronic daily cannabis smokers' blood on per se drugged driving laws. Clin. Chem. 2013, 59, 519.

[20] N.A. Desrosiers, S.K. Himes, K.B. Scheidweiler, M. Concheiro-Guisan, D.A. Gorelick, M.A. Huestis. Phase I and II cannabinoid disposition in blood and plasma of occasional and frequent smokers following controlled smoked cannabis. Clin. Chem. 2014, 60, 631.

[21] M. Fabritius, B. Favrat, H. Chtioui, G. Battistella, J.M. Annoni, M. Appenzeller, K. Dao, E. Fornari, E. Lauer, J.F. Mall, P. Maeder, P. Mangin, C. Staub, C. Giroud. THCCOOH concentrations in whole blood: are they useful in discriminating occasional from heavy smokers? Drug Test. Anal. 2014, 6, 155.

[22] T. Daldrup, H. Käferstein, H. Köhler, R.-D. Maier, F. Musshoff. Deciding between one off/occasional and regular cannabis consumption. Blutalkohol 2000, 37, 39.

[23] French Society of Analytical Toxicology (SFTA). Consensus Cannabis. 2013. Available at: http://www.sfta.org/img/uploads/2015/07/Consensus_cannabis_2013.pdf [12 August 2016].

[24] M. Fabritius, M. Augsburger, H. Chtioui, B. Favrat, C. Giroud. Fitness to drive and cannabis: validation of two blood THCCOOH thresholds to distinguish occasional users from heavy smokers. Forensic Sci. Int. 2014, 242, 1.

[25] D.M. Schwope, E.L. Karschner, D.A. Gorelick, M.A. Huestis. Identification of recent cannabis use: whole-blood and plasma free and glucuronidated cannabinoid pharmacokinetics following controlled smoked cannabis administration. Clin. Chem. 2011, 57, 1406. 
[26] M.E. Wall, H.L. Taylor. Conjugation of acidic metabolites of $\Delta-8$ and $\Delta-9-$ THC in man. in: Marihuana '84. Proceedings of the Oxford Symposium on Cannabis, (Ed: D.J. Harvey). IRL Press, Oxford, 1985, pp. 69-76.

[27] G. Skopp, L. Pötsch. Stability of 11-nor-delta(9)-carboxy-tetrahydrocannabinol glucuronide in plasma and urine assessed by liquid chromatography-tandem mass spectrometry. Clin. Chem. 2002, 48,301 .

[28] K.B. Scheidweiler, D.M. Schwope, E.L. Karschner, N.A. Desrosiers, D.A. Gorelick, M.A. Huestis. In vitro stability of free and glucuronidated cannabinoids in blood and plasma following controlled smoked cannabis. Clin. Chem. 2013, 59, 1108.

[29] M. Mauden, G. Skopp, R. Mattern, R. Aderjan. GC/MS-Bestimmung von THCCOOH im Serum: Vergleich verschiedener Aufarbeitungsmethoden und Einfluss von THCCOOHGlucuronid. Blutalkohol 2000, 37, 48.

[30] S. König, B. Aebi, S. Lanz, M. Gasser, W. Weinmann. On-line SPE LC-MS/MS for the quantification of Delta9-tetrahydrocannabinol (THC) and its two major metabolites in human peripheral blood by liquid chromatography tandem mass spectrometry. Anal. Bioanal. Chem. 2011, 400, 9 .

[31] K. Purschke, S. Heinl, O. Lerch, F. Erdmann, F. Veit. Development and validation of an automated liquid-liquid extraction GC/MS method for the determination of THC, 11-OH-THC, and free THC-carboxylic acid (THC-COOH) from blood serum. Anal. Bioanal. Chem. 2016, 408, 4379.

[32] M. Hädener, W. Weinmann, S. Schürch, S. König. Development of a rapid columnswitching LC-MS/MS method for the quantification of THCCOOH and THCCOOH-glucuronide in whole blood for assessing cannabis consumption frequency. Anal. Bioanal. Chem. 2016, 408, 1953.

[33] G. Battistella, E. Fornari, A. Thomas, J.F. Mall, H. Chtioui, M. Appenzeller, J.M. Annoni, B. Favrat, P. Maeder, C. Giroud. Weed or wheel! FMRI, behavioural, and toxicological investigations of how cannabis smoking affects skills necessary for driving. PloS one 2013, 8 , e52545.

[34] M. Fabritius, H. Chtioui, G. Battistella, J.M. Annoni, K. Dao, B. Favrat, E. Fornari, E. Lauer, P. Maeder, C. Giroud. Comparison of cannabinoid concentrations in oral fluid and whole blood between occasional and regular cannabis smokers prior to and after smoking a cannabis joint. Anal. Bioanal. Chem. 2013, 405, 9791.

[35] G. Battistella, E. Fornari, J.M. Annoni, H. Chtioui, K. Dao, M. Fabritius, B. Favrat, J.F. Mall, P. Maeder, C. Giroud. Long-term effects of cannabis on brain structure.

Neuropsychopharmacology 2014, 39, 2041.

[36] K. Hajian-Tilaki. Receiver Operating Characteristic (ROC) Curve Analysis for Medical Diagnostic Test Evaluation. Caspian J. Intern. Med. 2013, 4, 627. 
[37] A. Glaz-Sandberg, L. Dietz, H. Nguyen, H. Oberwittler, R. Aderjan, G. Mikus.

Pharmacokinetics of 11-nor-9-carboxy-Delta(9)-tetrahydrocannabinol (CTHC) after intravenous administration of CTHC in healthy human subjects. Clin. Pharmacol. Ther. 2007, 82, 63.

[38] D.S. Kreuz, J. Axelrod. Delta-9-tetrahydrocannabinol: localization in body fat. Science 1973, 179, 391.

[39] E. Johansson, K. Noren, J. Sjovall, M.M. Halldin. Determination of delta 1tetrahydrocannabinol in human fat biopsies from marihuana users by gas chromatography-mass spectrometry. Biomed. Chromatogr.1989, 3, 35.

[40] E. Johansson, M.M. Halldin, S. Agurell, L.E. Hollister, H.K. Gillespie. Terminal elimination plasma half-life of delta 1-tetrahydrocannabinol (delta 1-THC) in heavy users of marijuana. Eur. J. Clin. Pharmacol. 1989, 37, 273.

[41] E.R. Garrett. Pharmacokinetics and disposition of delta 9-tetrahydrocannabinol and its metabolites. Adv. Biosci. 1978, 22, 105.

[42] E.R. Garrett, C.A. Hunt. Pharmacokinetics of delta9-tetrahydrocannabinol in dogs. $J$. Pharm. Sci. 1977, 66, 395.

[43] A. Gronewold, G. Skopp. A preliminary investigation on the distribution of cannabinoids in man. Forensic Sci. Int. 2011, 210 , e7.

[44] M. Fabritius, C. Staub, P. Mangin, C. Giroud. Distribution of free and conjugated cannabinoids in human bile samples. Forensic Sci. Int. 2012, 223, 114.

[45] E. Böhnke, L. Dietz, T. Heinrich, R. Aderjan, G. Skopp, G. Mikus. Disposition and enterohepatic circulation of intravenously administered 11-nor-9-carboxy- $\Delta$ 9tetrahydrocannabinol in serum and urine in healthy human subjects. J. Forensic Toxicol. Pharmacol. 2013, 2, 2.

[46] A. Mazur, C.F. Lichti, P.L. Prather, A.K. Zielinska, S.M. Bratton, A. Gallus-Zawada, M. Finel, G.P. Miller, A. Radominska-Pandya, J.H. Moran. Characterization of human hepatic and extrahepatic UDP-glucuronosyltransferase enzymes involved in the metabolism of classic cannabinoids. Drug Metab. Dispos. 2009, 37, 1496.

[47] E. Blaak. Gender differences in fat metabolism. Curr. Opin. Clin. Nutr. Metab. Care. 2001, $4,499$. 


\section{Tables}

Table 1. Median (range) pharmacokinetic group comparison of THCCOOH-glucuronide and total THCCOOH in whole blood of heavy and occasional users before and after smoking

\begin{tabular}{ccccc}
\hline $\begin{array}{c}\text { Analyte and } \\
\text { parameter }\end{array}$ & $\begin{array}{c}\text { Heavy } \\
\text { smokers } \\
(n=23)\end{array}$ & $\begin{array}{c}\text { Occasional } \\
\text { smokers } \\
(n=25)\end{array}$ & $\begin{array}{c}\text { Mann-Whitney } \\
U\end{array}$ & $P$ \\
\hline \multicolumn{2}{l}{$\begin{array}{l}\text { Cannabis condition } \\
\text { THCCOOH-glucuronide }\end{array}$} & & & \\
$\mathrm{C}_{-5 \mathrm{~h}}(\mu \mathrm{g} / \mathrm{L})$ & $59.2(10.5-336.0)$ & $0(0-31.9)$ & 9 & $<0.0001$ \\
$\mathrm{C}_{0}(\mu \mathrm{g} / \mathrm{L})$ & $50.8(7.9-275.0)$ & $0(0-20.5)$ & 8 & $<0.0001$ \\
$\mathrm{C}_{\max }(\mu \mathrm{g} / \mathrm{L})$ & $59.7(20.8-358.0)$ & $15.9(<5-47.3)$ & 17 & $<0.0001$ \\
$\mathrm{t}_{\max }(\mathrm{h})$ & $2.0(0.3-3.5)$ & $2.6(1.5-2.9)$ & 256.5 & 0.5289 \\
$\mathrm{C}_{2.5 \mathrm{~h}}(\mu \mathrm{g} / \mathrm{L})$ & $59.2(18.6-316.0)$ & $15.1(<5-47.3)$ & 17.5 & $<0.0001$
\end{tabular}

THCCOOH total ${ }^{\mathrm{b}}$

$\begin{array}{lcccc}\mathrm{C}_{-5 \mathrm{~h}}(\mu \mathrm{g} / \mathrm{L}) & 69.7(10.9-377.3) & 0(0-32.7) & 10 & <0.0001 \\ \mathrm{C}_{0}(\mu \mathrm{g} / \mathrm{L}) & 60.5(8.1-279.4) & 0(0-20.5) & 9 & <0.0001 \\ \mathrm{C}_{\max }(\mu \mathrm{g} / \mathrm{L}) & 81.0(25.1-344.9) & 20.6(<3.3-48.5) & 13 & <0.0001 \\ \mathrm{t}_{\max }(\mathrm{h}) & 0.4(0.2-3.5) & 1.7(0.3-2.8) & 149 & 0.0037 \\ \mathrm{C}_{2.5 \mathrm{~h}}(\mu \mathrm{g} / \mathrm{L}) & 66.5(20.2-289.0) & 17.5(<3.3-48.0) & 25 & <0.0001\end{array}$

Placebo condition

THCCOOH-glucuronide ${ }^{\mathrm{a}}$

$\begin{array}{lllll}\mathrm{C}_{-5 \mathrm{~h}}(\mu \mathrm{g} / \mathrm{L}) & 41.5(<5-191.0) & 0(0-51.5) & 16 & <0.0001 \\ \mathrm{C}_{0}(\mu \mathrm{g} / \mathrm{L}) & 33.1(<5-152.0) & 0(0-40.5) & 27 & <0.0001 \\ \mathrm{C}_{2.5 \mathrm{~h}}(\mu \mathrm{g} / \mathrm{L}) & 32.7(<5-119.0) & 0(0-33.9) & 24 & <0.0001\end{array}$

THCCOOH total ${ }^{\mathrm{b}}$

$\begin{array}{lllcl}\mathrm{C}_{-5 \mathrm{~h}}(\mu \mathrm{g} / \mathrm{L}) & 47.8(3.9-269.4) & 0(0-57.9) & 15 & <0.0001 \\ \mathrm{C}_{0}(\mu \mathrm{g} / \mathrm{L}) & 32.9(4.9-168.6) & 0(0-48.2) & 25 & <0.0001 \\ \mathrm{C}_{2.5 \mathrm{~h}}(\mu \mathrm{g} / \mathrm{L}) & 31.4(3.5-150.9) & 0(0-42.5) & 27.5 & <0.0001\end{array}$

${ }^{\mathrm{a}} \mathrm{LLOQ}$ was $5 \mu \mathrm{g} / \mathrm{L}$

${ }^{\mathrm{b}}$ LLOQ was $3.3 \mu \mathrm{g} / \mathrm{L}$ 
Table 2. Diagnostic characteristics of THCCOOH, THCCOOH-glucuronide and total THCCOOH concentrations thresholds

\begin{tabular}{|c|c|c|c|}
\hline Analyte & Blood level $(\mu \mathrm{g} / \mathrm{L})$ & Sensitivity (\%) & Specificity (\%) \\
\hline \multicolumn{4}{|c|}{ Heavy smokers rule out thresholds } \\
\hline THCCOOH free ${ }^{a}$ & $<3$ & 97 & 62 \\
\hline THCCOOH-glucuronide & $<5$ & 97 & 73 \\
\hline THCCOOH total & $<5$ & 98 & 62 \\
\hline \multicolumn{4}{|c|}{ Heavy smokers rule in thresholds } \\
\hline THCCOOH free ${ }^{a}$ & $>40$ & 16 & 100 \\
\hline THCCOOH-glucuronide & $>52$ & 41 & 100 \\
\hline THCCOOH total & $>58$ & 43 & 100 \\
\hline
\end{tabular}

${ }^{a}$ Data reported by Fabritius et al. ${ }^{[2]]}$ 


\section{Figures}
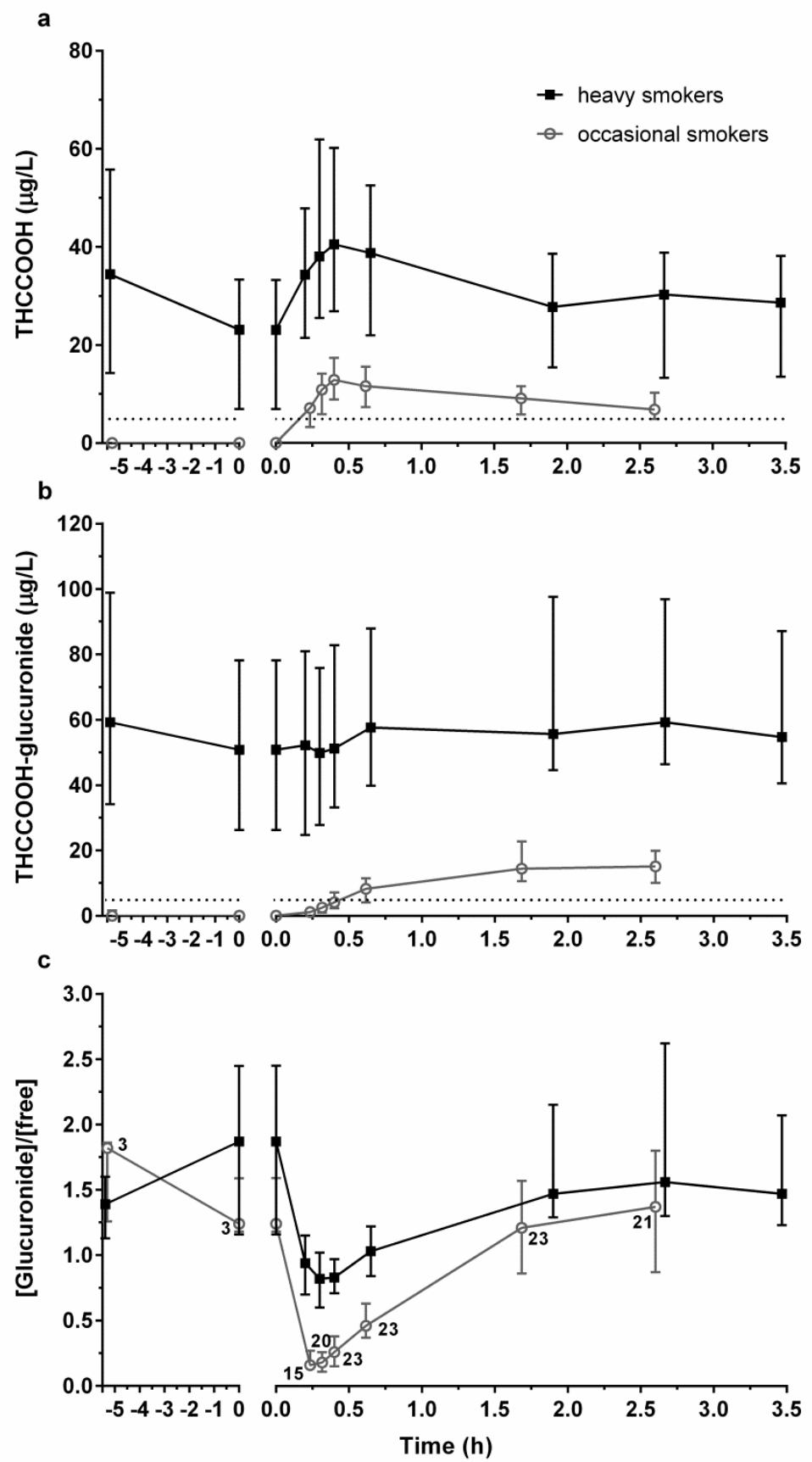

Figure 1. Median (interquartile) time profiles of a THCCOOH, b THCCOOH-glucuronide, and $\mathbf{c}$ molar THCCOOH-glucuronide-to-THCCOOH ratios in whole blood of 25 occasional and 23 heavy users before and after smoking of a cannabis cigarette. Dotted lines indicate limits of quantification $(5 \mu \mathrm{g} / \mathrm{L}$ each) and $n$ values indicate data points for occasional users' ratios (for heavy users, $n=23$ at all times). 


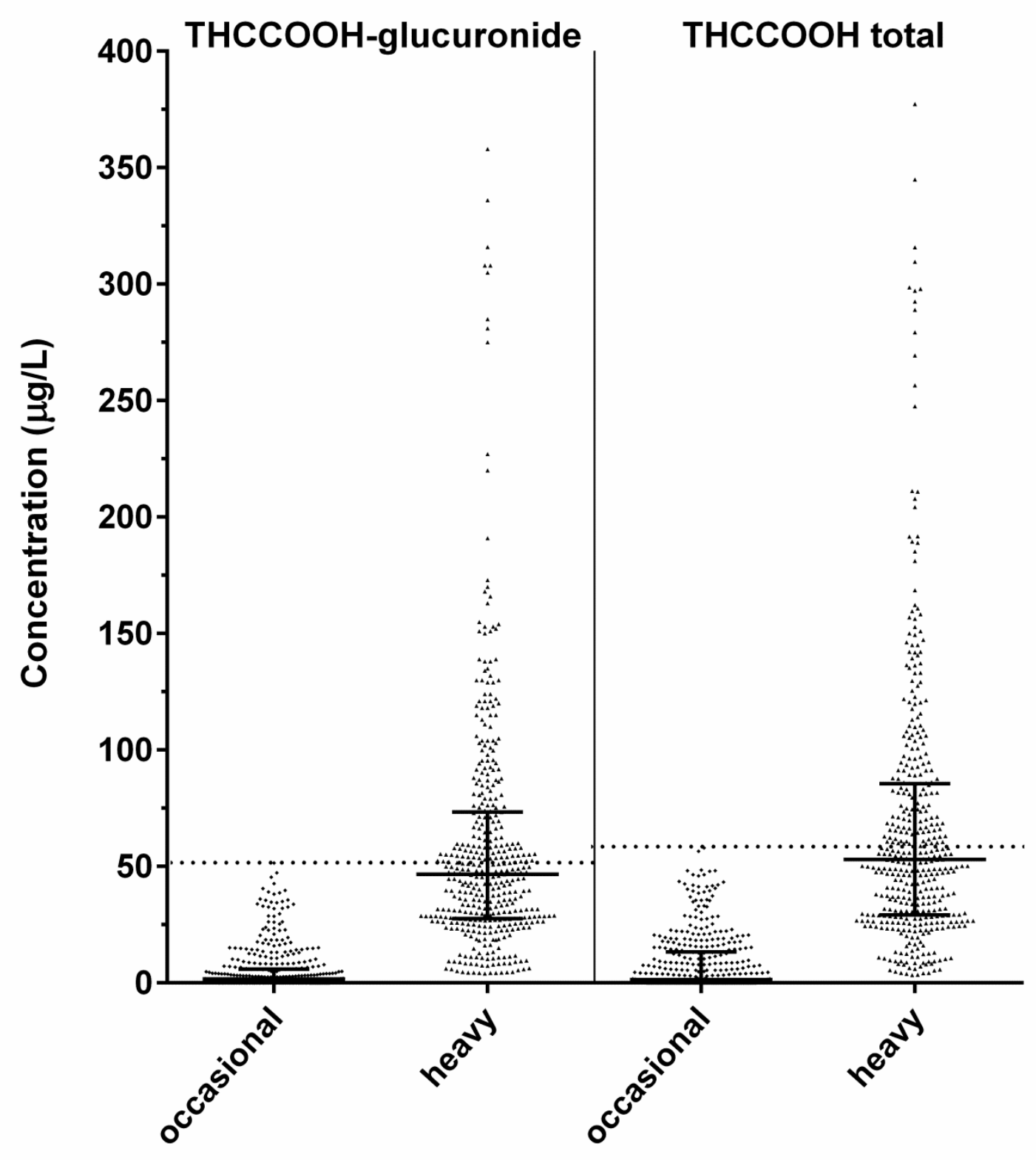

Figure 2. Scatter plot (median and interquartile) comparing the distribution of THCCOOHglucuronide and total THCCOOH concentrations in whole blood samples of occasional and heavy users measured throughout the study (occasional: $n=418$; heavy: $n=422$ ). Dotted lines indicate occasional users' maximum concentrations (51.6 and $57.9 \mu \mathrm{g} / \mathrm{L}$, respectively). MannWhitney test revealed significant differences between occasional and heavy users' blood levels (two-tailed $P<0.0001$ ). 

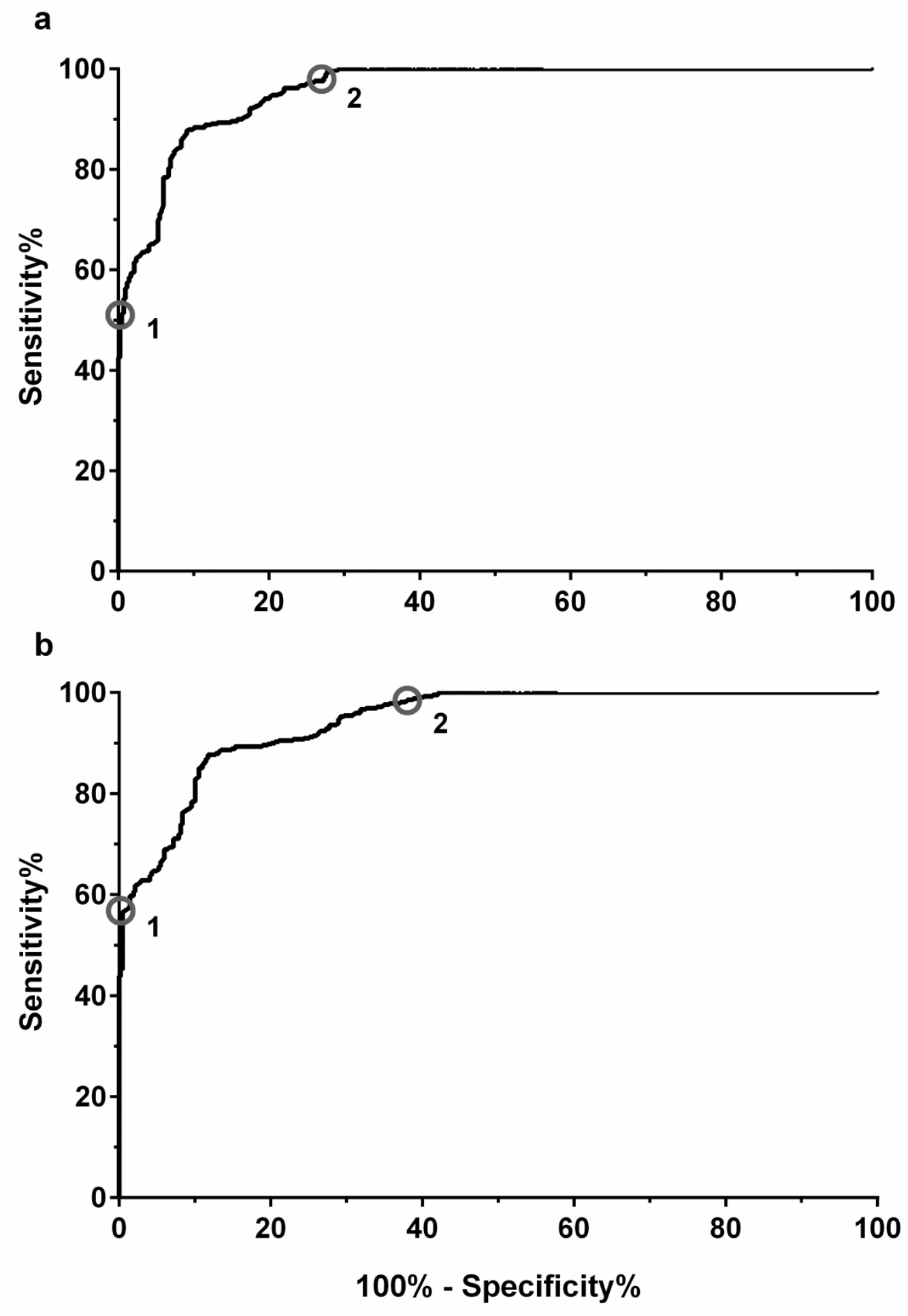

Figure 3. ROC curves of $\mathbf{a} \mathrm{THCCOOH}$-glucuronide and $\mathbf{b}$ total $\mathrm{THCCOOH}$ concentrations in whole blood samples measured throughout the study $(n=840)$. Circle $1=$ threshold to rule in heavy users $(52 \mu \mathrm{g} / \mathrm{L}$ and $58 \mu \mathrm{g} / \mathrm{L}$, respectively), Circle $2=$ threshold to rule out heavy users $(5$ $\mu \mathrm{g} / \mathrm{L}$ each). 


\section{Supporting Information}

Table S1. Demographic characteristics, self-reported histories of cannabis use and measured cannabinoid concentrations for 23 heavy smokers

\begin{tabular}{|c|c|c|c|c|c|c|c|c|c|c|c|c|c|c|c|}
\hline \multirow{3}{*}{ Participant } & \multirow{3}{*}{ Ethnicity } & \multirow{3}{*}{$\begin{array}{c}\text { Age on } \\
\text { admission }\end{array}$} & \multirow{3}{*}{$\begin{array}{c}\text { Body } \\
\text { mass } \\
\text { index }\end{array}$} & \multirow{3}{*}{$\begin{array}{c}\text { Age } \\
\text { at first } \\
\text { use }^{b}\end{array}$} & \multirow{3}{*}{$\begin{array}{c}\text { Lifetime } \\
\text { years } \\
\text { smoked }^{b}\end{array}$} & \multirow{3}{*}{$\begin{array}{c}\begin{array}{c}\text { Frequency of use }^{b} \\
\text { (times/week, } \\
\text { last three weeks) }\end{array}\end{array}$} & \multicolumn{9}{|c|}{ Cannabinoid concentrations $(\mu \mathrm{g} / \mathrm{L}$ ) } \\
\hline & & & & & & & \multicolumn{3}{|c|}{ at screening visit } & \multicolumn{3}{|c|}{ during cannabis session $^{d}$} & \multicolumn{3}{|c|}{ during placebo session $^{d}$} \\
\hline & & & & & & & $\begin{array}{c}\mathrm{THCCOOH} \\
\text { free }\end{array}$ & $\begin{array}{l}\mathrm{THCCOOH}- \\
\text { glucuronide }\end{array}$ & $\begin{array}{c}\mathrm{THCCOOH} \\
\text { total }\end{array}$ & $\begin{array}{l}\mathrm{THCCOOH} \\
\text { free }\end{array}$ & $\begin{array}{l}\text { THCCOOH- } \\
\text { glucuronide }\end{array}$ & $\begin{array}{c}\mathrm{THCCOOH} \\
\text { total }\end{array}$ & $\begin{array}{c}\mathrm{THCCOOH} \\
\text { free }\end{array}$ & $\begin{array}{l}\mathrm{THCCOOH}- \\
\text { glucuronide }\end{array}$ & $\begin{array}{c}\mathrm{THCCOOH} \\
\text { total }\end{array}$ \\
\hline 1 & $E^{a}$ & 21 & 23,2 & 15 & 6 & 5 & e & e & e & $<$ LLOQ - 31.2 & $16.1-47.9$ & $16.6-51.6$ & $9.7-24.4$ & $22.5-35.0$ & $24.6-47.6$ \\
\hline 2 & E/AF & 22 & 22,1 & 14 & 8 & 14 & e & e & e & $43.0-83.9$ & $84.9-106.0$ & $109.8-142.1$ & $24.5-34.4$ & $45.2-68.2$ & $54.6-79.5$ \\
\hline 3 & $\mathrm{E}$ & 20 & 19,0 & 16 & 4 & 5 & 20,2 & 56,4 & 57,5 & $10.1-31.1$ & $38.9-66.9$ & $37.3-62.3$ & $12.8-31.0$ & $49.5-81.6$ & $48.1-85.0$ \\
\hline 4 & $\mathrm{E}$ & 20 & 20,0 & 16 & 4 & 20 & e & e & e & $20.4-50.1$ & $61.3-87.2$ & $61.0-91.3$ & $10.6-17.8$ & $31.7-45.6$ & $33.8-48.0$ \\
\hline 5 & $\mathrm{AF}$ & 22 & 22,8 & 19 & 3 & 16 & e & e & e & $6.2-25.5$ & $23.7-49.0$ & $24.3-51.8$ & $6.0-9.7$ & $23.3-32.1$ & $22.1-31.0$ \\
\hline 6 & $\mathrm{E}$ & 22 & 22,5 & 19 & 3 & 20 & 9,2 & 25,7 & 26,2 & $5.1-25.0$ & $18.8-39.8$ & $17.6-41.0$ & $<$ LLOQ & $8.1-12.8$ & $8.1-12.6$ \\
\hline 7 & $\mathrm{E}$ & 25 & 23,0 & 12 & 13 & 20 & 97,4 & 227,0 & 247,6 & \begin{tabular}{|c|}
$79.9-155.0$ \\
\end{tabular} & $275.0-358.0$ & $279.4-377.3$ & e & e & e \\
\hline 8 & $\mathrm{E}$ & 19 & 21,8 & 15 & 4 & $60^{c}$ & $<$ LLOQ & 19,6 & 15,8 & $8.5-23.3$ & $26.5-45.6$ & $27.6-46.9$ & $7.2-16.7$ & $26.8-38.9$ & $26.1-42.4$ \\
\hline 9 & $\mathrm{AF}$ & 27 & 22,7 & 19 & 8 & 20 & 27,6 & 50,4 & 60,9 & $19.2-37.7$ & $39.5-54.3$ & $51.7-66.4$ & $7.9-16.0$ & $20.6-31.6$ & $22.6-36.9$ \\
\hline 10 & $E$ & 24 & 18,9 & 15 & 9 & $42^{c}$ & 63,0 & 124,0 & 145,0 & $38.5-88.3$ & $115.0-153.0$ & $120.6-189.5$ & $21.8-42.1$ & $58.2-92.6$ & $60.7-93.6$ \\
\hline 11 & $\mathrm{E}$ & 25 & 21,8 & 15 & 10 & $50^{c}$ & 164,0 & 220,0 & 309,6 & $80.4-154.0$ & $139.0-173.0$ & $181.1-256.6$ & $54.9-143$ & 119 - 191 & $145.1-269.4$ \\
\hline 12 & $E$ & 21 & 21,4 & 18 & 3 & 18 & 35,3 & 76,2 & 85,7 & $26.9-67.1$ & $33.3-62.5$ & $60.5-98.5$ & $21.5-42.3$ & $58.5-132.0$ & $63.0-129.6$ \\
\hline 13 & $\mathrm{E}$ & 22 & 21,1 & 14 & 8 & $25^{c}$ & 10,4 & 31,0 & 30,9 & $5.3-30.5$ & $21.5-47.5$ & $19.6-53.6$ & $5.4-16.5$ & $22.3-36.3$ & $21.0-40.5$ \\
\hline 14 & $\mathrm{E}$ & 24 & 26,1 & 20 & 4 & 10 & 19,5 & 54,9 & 55,8 & $10.5-34.4$ & $66.4-79.2$ & $55.3-80.2$ & < LLOQ - 7.1 & $27.0-37.5$ & $23.3-31.9$ \\
\hline 15 & E/AS & 20 & 21,6 & 12 & 8 & $28^{c}$ & 17,7 & 38,8 & 43,4 & $40.2-86.6$ & $69.2-103.0$ & $86.0-136.4$ & $21.0-36.9$ & $44.6-71.1$ & $55.3-76.3$ \\
\hline 16 & E & 25 & 22,3 & 19 & 6 & 6 & 12,5 & 37,7 & 37,4 & $6.8-30.7$ & $18.9-33.4$ & $23.4-49.2$ & $2.6-6.5$ & $8.0-11.3$ & $9.2-13.8$ \\
\hline 17 & E & 23 & 21,4 & 15 & 8 & $30^{c}$ & 30,4 & 115,0 & 106,5 & $23.1-76.5$ & $94.4-170.0$ & $86.2-189.0$ & $21.4-51.0$ & $111.0-166.0$ & $96.2-160.8$ \\
\hline 18 & $E$ & 25 & 20,4 & 20 & 5 & $25^{c}$ & 61,8 & 121,0 & 141,9 & $31.2-53.0$ & $53.0-59.2$ & $66.7-91.3$ & $17.5-29.3$ & $39.3-55.0$ & $45.6-65.7$ \\
\hline 19 & $\mathrm{E}$ & 22 & 18,1 & 15 & 7 & 14 & 44,3 & 134,0 & 133,0 & $35.1-62.2$ & 76.4 - 99.8 & $91.4-123.0$ & $13-29.1$ & $44.9-57.6$ & $46.2-65.6$ \\
\hline 20 & $\mathrm{E}$ & 24 & 26,4 & 15 & 9 & 16 & 22,6 & 57,8 & 60,8 & | LLLOQ - 11.7 & $7.4-20.8$ & $8.1-25.1$ & $<\mathrm{LLOQ}$ & $<\mathrm{LLOQ}$ & $3.4-4.9$ \\
\hline 21 & E & 20 & 20,4 & 16 & 4 & 15 & 19,8 & 25,2 & 36,5 & $7.2-53.0$ & $11.5-28.5$ & $14.8-62.7$ & $0-7.5$ & $<$ LLOQ -7.4 & $4.1-12.3$ \\
\hline 22 & $\mathrm{E}$ & 23 & 18,0 & 15 & 8 & $25^{c}$ & 16,0 & 31,7 & 37,0 & $29.2-48.2$ & $49.8-77.2$ & $63.8-82.7$ & $5.6-14.5$ & $20.0-35.5$ & $21.3-37.0$ \\
\hline 23 & $\mathrm{E}$ & 24 & 21,8 & 15 & 9 & 12 & $<$ LLOQ & 8,4 & 8,2 & $27.8-49.0$ & $46.6-55.6$ & $61.7-81.0$ & $19.8-32.9$ & $38.7-44.1$ & $46.5-61.8$ \\
\hline Mean & & 22,6 & 21,6 & 16,0 & 6,6 & 21,6 & & & & & & & & & \\
\hline SD & & 2,1 & 2,1 & 2,3 & 2,7 & 13,7 & & & & & & & & & \\
\hline Median & & 22,0 & 21,8 & 15,0 & 7,0 & 20,0 & & & & & & & & & \\
\hline
\end{tabular}

${ }^{a} \mathrm{E}$, European; AF, African; AS, Asian.

${ }^{\mathrm{b}}$ Data collected on admission.

' Self-reported average use at screening was $<3$ joints/day.

Range of concentrations measured on admission ( $5 \mathrm{~h}$ before smoking), a few minutes before inhalation, and $0.2,0.3,0.4,0.65,1.9,2.5$, and $3.5 \mathrm{~h}$ after the start of smoking.

${ }^{e}$ Not measured due to lack of sample material for re-analysis. 
Table S2. Demographic characteristics, self-reported histories of cannabis use and measured cannabinoid concentrations for 25 occasional smokers

\begin{tabular}{|c|c|c|c|c|c|c|c|c|c|c|c|c|c|c|c|}
\hline \multirow{3}{*}{ Participant } & \multirow{3}{*}{ Ethnicity } & \multirow{3}{*}{$\begin{array}{c}\text { Age on } \\
\text { admission }\end{array}$} & \multirow{3}{*}{$\begin{array}{l}\text { Body } \\
\text { mass } \\
\text { index }\end{array}$} & \multirow{3}{*}{$\begin{array}{c}\text { Age } \\
\text { at first } \\
\text { use }^{\text {b }}\end{array}$} & \multirow{3}{*}{$\begin{array}{c}\text { Lifetime } \\
\text { years } \\
\text { smoked }^{b}\end{array}$} & \multirow{3}{*}{$\begin{array}{c}\text { Frequency of use } \\
\text { (times/month, } \\
\text { last three months) }\end{array}$} & \multicolumn{9}{|c|}{ Cannabinoid concentrations $(\mu \mathrm{g} / \mathrm{L})$} \\
\hline & & & & & & & \multicolumn{3}{|c|}{ at screening visit } & \multicolumn{3}{|c|}{ during cannabis session ${ }^{\dagger}$} & \multicolumn{3}{|c|}{ during placebo session $^{f}$} \\
\hline & & & & & & & $\begin{array}{c}\mathrm{THCCOOH} \\
\text { free }\end{array}$ & \begin{tabular}{|l} 
THCCOOH- \\
glucuronide
\end{tabular} & $\begin{array}{c}\mathrm{THCCOOH} \\
\text { total }\end{array}$ & $\begin{array}{c}\mathrm{THCCOOH} \\
\text { free }\end{array}$ & $\begin{array}{c}\text { THCCOOH- } \\
\text { glucuronide }\end{array}$ & $\begin{array}{c}\mathrm{THCCOOH} \\
\text { total }\end{array}$ & $\begin{array}{l}\mathrm{THCCOOH} \\
\text { free }\end{array}$ & $\begin{array}{l}\text { THCCOOH- } \\
\text { glucuronide }\end{array}$ & $\begin{array}{c}\text { THCCOOH } \\
\text { total }\end{array}$ \\
\hline 1 & $E^{a}$ & 23 & 25,5 & 13 & 10 & 2 & 0 & 0 & 0 & $0-6.2$ & $0-5.9$ & $0-7.9$ & 0 & 0 & 0 \\
\hline 2 & E & 24 & 24,4 & 9 & 15 & 4 & 0 & 0 & 0 & $0-8.9$ & $0-14.4$ & $0-16.1$ & 0 & $0-<$ LLOQ & $0-<$ LLOQ \\
\hline 3 & AS & 26 & 22,4 & 23 & 4 & 2 & 0 & 0 & 0 & $0-14.9$ & $0-13.3$ & $0-19.0$ & 0 & $0-<$ LLOQ & $0-<$ LLOQ \\
\hline 4 & E & 25 & 21,8 & 14 & 11 & 1 & 0 & 0 & 0 & $0-11.0$ & $0-11.3$ & $0-12.5$ & 0 & $0-<$ LLOQ & $0-<$ LLOQ \\
\hline 5 & E & 26 & 21,2 & 18 & 8 & 1 & 0 & 0 & 0 & $0-18.8$ & $0-14.9$ & $0-20.9$ & 0 & 0 & 0 \\
\hline 6 & $\mathrm{E}$ & 28 & 18,8 & 18 & 10 & 2 & 0 & 0 & 0 & $0-11.5$ & $0-6.4$ & $0-12.7$ & 0 & 0 & 0 \\
\hline 7 & $\mathrm{E}$ & 26 & 21,9 & 20 & 6 & 4 & 0 & 0 & 0 & $0-15.1$ & $0-16.8$ & $0-22.0$ & 0 & $0-<$ LLOQ & $0-<$ LLOQ \\
\hline 8 & $\mathrm{E}$ & 26 & 18,0 & 14 & 12 & $8^{c}$ & 0 & 0 & 0 & $0-20.0$ & $<$ LLOQ - 32.1 & $<$ <LLOQ - 33.0 & 0 & $<$ LLOQ & $<L L O Q$ \\
\hline 9 & $\mathrm{E}$ & 27 & 18,5 & 17 & 10 & $5^{c}$ & $<L L O Q$ & $<$ LLOQ & 4,2 & $0-21.8$ & $<$ LLOQ - 32.6 & $<$ LLOQ -39.5 & 0 & 0 & 0 \\
\hline 10 & $E$ & 24 & 22,1 & 17 & 7 & $5^{c}$ & 0 & 0 & 0 & $0-12.9$ & $<$ LLOQ-28.6 & $<$ LLOQ - 28.9 & 0 & $<L L O Q$ & $<L L O Q$ \\
\hline 11 & $E$ & 19 & 20,3 & 13 & 6 & 4 & 0 & 0 & 0 & $0-25.6$ & $0-18.6$ & $0-28.4$ & 0 & $0-<$ LLOQ & $0-<$ LLOQ \\
\hline 12 & $\mathrm{E}$ & 25 & 24,2 & 21 & 4 & $6^{\mathrm{c}}$ & 0 & 0 & 0 & $0-12.3$ & $0-17.1$ & $0-20.2$ & 0 & $0-<$ LLOQ & $0-<$ LLOQ \\
\hline 13 & E & 19 & 22,9 & 15 & 4 & 4 & $<L L O Q$ & $<$ LLOQ & 4,2 & $0-16.6$ & < LLOQ - 18.5 & $\begin{array}{l}<\text { LLOQ - } 25.4 \\
\end{array}$ & $<L L O Q$ & $<$ LLOQ & $3.4-4.8$ \\
\hline 14 & $\mathrm{E}$ & 27 & 21,6 & 19 & 8 & $5^{c}$ & 0 & 6,9 & 4,5 & $7.3-32.2$ & $12.5-23.9$ & $15.6-48.0$ & 0 & $8.2-10.6$ & $5.4-7.0$ \\
\hline 15 & $E$ & 24 & 25,7 & 18 & 6 & 2 & 0 & 0 & 0 & $0-14.2$ & $0-15.9$ & $0-17.8$ & 0 & 0 & 0 \\
\hline 16 & $E$ & 20 & 23,5 & 14 & 6 & 1 & $\mathrm{~g}$ & $\mathrm{~g}$ & $\mathrm{~g}$ & $0-0$ & $0-2.6$ & $0-1.7$ & 0 & 0 & 0 \\
\hline 17 & $\mathrm{E} / \mathrm{AF}$ & 29 & 29,1 & 18 & 11 & 1 & $<$ LLOQ & $<L L O Q$ & 3,9 & $0-18.9$ & $0-12.0$ & $0-20.6$ & $<$ LLOQ & $<L L O Q$ & $<$ LLOQ - 4.2 \\
\hline 18 & $E$ & 25 & 21,5 & 15 & 10 & $8^{c}$ & 0 & 0 & 0 & $0-8.8$ & $0-4.9$ & $0-10.2$ & 0 & $0-<$ LLOQ & $0-<$ LLOQ \\
\hline 19 & $\mathrm{E}$ & 22 & 22,0 & 16 & 6 & $<1^{d}$ & $\mathrm{~g}$ & $\mathrm{~g}$ & $\mathrm{~g}$ & $0-0$ & $0-3.1$ & $0-2.1$ & 0 & 0 & 0 \\
\hline 20 & E & 20 & 22,1 & 15 & 5 & $5^{c}$ & 28,4 & 42,6 & 56,5 & $7.3-23.7$ & $13.7-39.1$ & $16.4-46.5$ & $11.9-25.2$ & $32.6-38.1$ & $34.9-48.2$ \\
\hline 21 & E & 20 & 24,2 & 16 & 4 & 3 & 0 & 0 & 0 & $0-11.0$ & $0-15.0$ & $0-16.6$ & 0 & 0 & 0 \\
\hline 22 & E & 21 & 27,8 & 17 & 4 & 3 & 0 & 0 & 0 & $0-5.4$ & $0-5.8$ & $0-8.6$ & 0 & 0 & 0 \\
\hline 23 & $E$ & 21 & 23,5 & 14 & 7 & 2 & 0 & 0 & 0 & $0-12.6$ & $0-26.3$ & $0-24.0$ & 0 & 0 & 0 \\
\hline 24 & $E$ & 22 & 20,6 & 18 & 5 & 4 & 0 & 0 & 0 & $0-13.9$ & $<$ LLOQ - 17.6 & $\begin{array}{ll}<\text { <LOQ - } 20.8 \\
\end{array}$ & 0 & $0-<$ LLOQ & $0-<$ LLOQ \\
\hline 25 & $\mathrm{E}$ & 28 & 19,8 & 16 & 12 & e & $<L L O Q$ & $<L L O Q$ & 5,6 & $7.0-31.5$ & $18.5-47.3$ & $20.5-48.5$ & $15.9-23.9$ & $33.0-51.5$ & $35.6-57.9$ \\
\hline Mean & & 23,9 & 22,5 & 16,3 & 7,6 & 3,5 & & & & & & & & & \\
\hline SD & & 3,0 & 2,7 & 2,9 & 3,1 & 2,3 & & & & & & & & & \\
\hline Median & & 24,0 & 22,1 & 16,0 & 7,0 & 3,5 & & & & & & & & & \\
\hline
\end{tabular}

${ }^{\mathrm{a}} \mathrm{E}$, European; AF, African; AS, Asian.

${ }^{b}$ Data collected on admission

'S Self-reported average use at screening was $\leq 1$ joint/week.

${ }^{\mathrm{d}}$ Self-reported average use at screening was $\geq 1$ joint/month.

' Data not collected.

${ }^{\mathrm{f}}$ Range of concentrations measured on admission ( $5 \mathrm{~h}$ before smoking), a few minutes before inhalation, and $0.2,0.3,0.4,0.65,1.9$, and $2.5 \mathrm{~h}$ after the start of smoking.

${ }^{8}$ Not measured due to lack of sample material for re-analysis. 